\title{
Physical Properties of Lithium Containing Cadmium Phosphate Glasses
}

\author{
Muhammad Altaf ${ }^{1}$, M. Ashraf Chaudhry ${ }^{2}$ \\ ${ }^{1}$ Department of Physics, Govt. College of Science, Multan, Pakistan \\ ${ }^{2}$ Department of Physics, Bahauddin Zakariya University, Multan, Pakistan \\ E-mail:altaf_sal@yahoo.com \\ Received May 1, 2010; revised August 15, 2010; accepted May 14, 2010
}

\begin{abstract}
Lithium cadmium phosphate glasses were prepared by melt quench technique. These glasses contain a mole $\%$ composition of $\mathrm{x} \% \mathrm{Li}_{2} \mathrm{O}-(50-\mathrm{x}) \% \mathrm{CdO}-50 \% \mathrm{P}_{2} \mathrm{O}_{5}$. The quantity $\mathrm{x}$ varies from $0-40$ mole $\%$. The physical properties reported in this paper are mass density $\rho$, modulus of rigidity $\eta$, coefficient of linear expansion $\alpha$, transition temperature $T_{g}$, Softening temperature $T_{s}$, Oxygen packing density, Molar volume and lithium ion concentration. The mass density, oxygen packing density, modulus rigidity, transition temperature and softening temperature show decreasing trend with increasing concentration of lithium ions in these glasses, where molar volume and coefficient of linear expansion increases with increasing concentration of $\mathrm{Li}_{2} \mathrm{O}$.
\end{abstract}

Keywords: Phosphate Glasse, Mass Density, Modulus of Rigidity, Coefficient of Linear Expansion, Transition Temperature, Molar Volume

\section{Introduction}

The competition of speed, cost and reliability of electronic devices in various applications has led to the research for new materials which can met the specific requirement. The phosphate glasses are among those materials which have a number of technical and biological applications [1-3]. Phosphate glasses have a variety of technological application due to several unique properties [4]. To investigate the nature of these glasses for their appropriate applications, study of optical, electrical and physical properties are necessary. Most of the researchers studied optical and electrical properties to characterize the phosphate glasses [5-8], whereas the knowledge of physical properties is equally very helpful to study the nature of materials.

A general observation of the thermal expansion curve tells whether the materials under investigation are amorphous are crystalline in nature. Experimental results on physical properties in glassy material have been reported in literature [9-11].

In the present work physical properties such as mass density, oxygen packing density, molar volume, modulus of rigidity, transition temperature, softening temperature and coefficient of linear expansion were studied to examine the effect of alkali metal oxide i.e. $\mathrm{Li}_{2} \mathrm{O}$ on the cadmium phosphate glasses. According to our survey, no data has been reported on the physical properties of cadmium phosphate glass system containing lithium oxide.

\section{Experimental}

Chemicals $\mathrm{Li}_{2} \mathrm{CO}_{3}, \mathrm{CdO}$ and $\mathrm{P}_{2} \mathrm{O}_{5}$ of purity $(99.99 \%)$ were used to prepare Lithium-cadmium-phosphate glasses. The glass samples were prepared by using $15 \mathrm{~g}$ ingredients mixture of composition $\mathrm{x} \% \mathrm{Li}_{2} \mathrm{O}-(50-\mathrm{x}) \% \mathrm{CdO}-50 \% \mathrm{P}_{2} \mathrm{O}_{5}$ in a platinum crucible. The details of preparation of samples and method of density measurements and modulus of rigidity have already been described else where $[12,13]$. Oxygen packing density, molar volume and lithium ion concentration were estimated by using following equations respectively,

$$
\begin{gathered}
\text { Oxygen packing density }=\{1000 \times \rho \times(\mathrm{O})\} / \mathrm{M} \\
\text { Molar volume }=\mathrm{M} / \rho \\
\text { Ion concentration }=\left\{\rho \mathrm{N}_{\mathrm{avo}} \mathrm{P}\right\} / \mathrm{M}
\end{gathered}
$$

where $\rho=$ mass density

$\mathrm{M}=$ Molecular weight of glass composition

$\mathrm{O}=$ number of oxygen atoms in the composition

$\mathrm{N}_{\mathrm{avo}}=$ Avogadro number

and $\mathrm{P}=\mathrm{nx}$

where ' $\mathrm{x}$ ' is the mole fraction in glass composition and 
' $\mathrm{n}$ ' is the number of atoms of element ions in a given oxide, i.e. $\mathrm{n}=1$ for oxides like $\mathrm{CdO}, \mathrm{ZnO}$ etc and $\mathrm{n}=2$ for oxides like $\mathrm{Li}_{2} \mathrm{O}, \mathrm{Na}_{2} \mathrm{O}$, etc.

Thermal expansion and coefficient of linear expansion of fibers of lithium phosphate glasses have been studied up to $600^{\circ} \mathrm{C}$. These parameters were measured by using a horizontal tube heating system as shown in Figure 1. The heating system consists of two equal bore Pyrex tubes each of $10 \mathrm{~cm}$ length. The tubes are fitted together in a single heating unit so that both the tubes can have the same temperature. A Cromel-Alumel thermocouple connected to a Fenwal controller is fitted in one tube and the glass fiber ' $\mathrm{F}$ ' of length $\mathrm{L}_{\mathrm{o}}=10.5 \mathrm{~cm}$ is placed in the other tube. The temperature of the system is controlled by a temperature controller while the heating rate is controlled through a voltage regulator. Each temperature was maintained for five minutes to achieve the equilibrium.

The increase in the length of the fiber for every $50^{\circ} \mathrm{C}$ rise in temperature (with constant rate of heating) was measured with a traveling microscope whose least count is $10 \mu \mathrm{m}$. The linear expansion was plotted against temperature as shown in Figure 2. This curve was used to estimate transition temperature $\mathrm{Tg}$ and softening temperature Ts. The coefficient of linear expansion ' $\alpha$ ' is then calculated using equation

$$
\alpha=(\Delta \mathrm{L}) /(\operatorname{Lo} \Delta \mathrm{t})\left({ }^{\circ} \mathrm{C}\right)^{-1}
$$

\section{Results and Discussion}

The measured results and estimated values of mass density are listed in Table 1 . These results indicate a decreasing trend in the density of. $\mathrm{x} \% \mathrm{Li}_{2} \mathrm{O}-(50-\mathrm{x}) \%$ $\mathrm{CdO}-50 \% \mathrm{P}_{2} \mathrm{O}_{5}$ glass system with increasing concentration of $\mathrm{Li}_{2} \mathrm{O}$. Theoretical values of the density were estimated by using the relation $\rho=\sum \rho_{i} x_{i}$, where $\rho_{i}$ and $x_{i}$ are the density and fraction of the free oxides respectively. The estimated and the measured values of density of these glasses are depicted in Figure $\mathbf{3}$ as a function of $\mathrm{Li}_{2} \mathrm{O}$ concentration. It can be seen that estimated values are higher than measured values. This difference in values of density may be due to the variation in atomic arrangement between the structure of glass and molecules of the free oxides. The decrease in the measured density with the increasing concentration of $\mathrm{Li}_{2} \mathrm{O}$ agrees qualitatively with that predicted by the composition relation, and it may be due to the replacement of high density $\mathrm{CdO}\left(8.15 \mathrm{~g} / \mathrm{cm}^{3}\right)$ as compared with $\mathrm{Li}_{2} \mathrm{O}\left(2.02 \mathrm{~g} / \mathrm{cm}^{3}\right)$. The estimated oxygen packing density and molar volume and lithium ion concentration are listed in Table $\mathbf{1}$ and are shown in Figures 4, 5, and 6 respectively. These results show that oxygen packing density decreases where as molar volume and lithium ion concentration increase

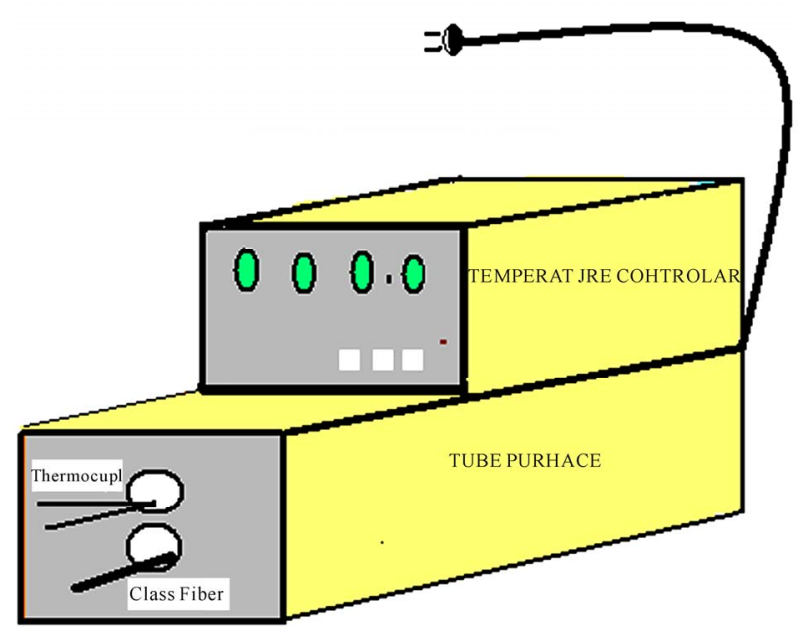

Figure 1. Tube furnace along with temperature controller for heating the fiber to measure its linear expansion with the variation temperature.

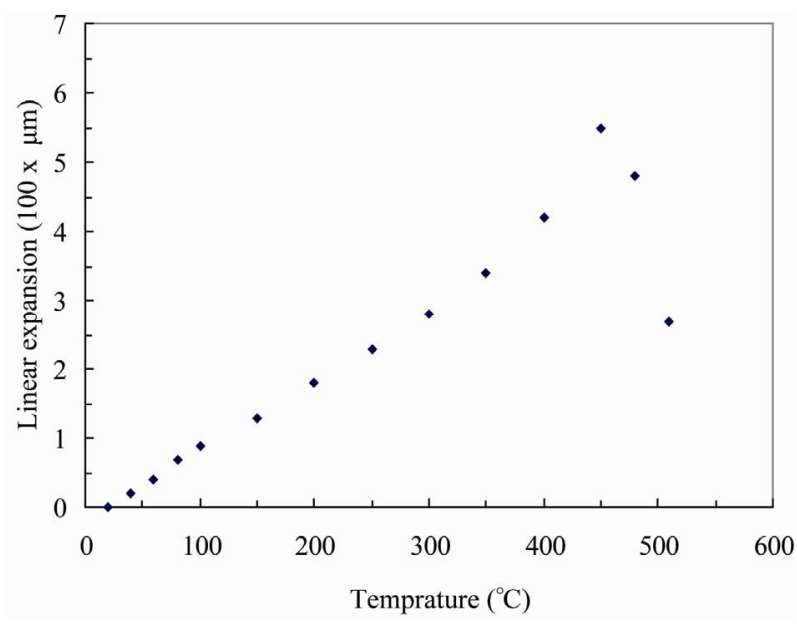

Figure 2. A plot of linear expansion $\Delta \mathrm{l}$ versus temperature ${ }^{\circ} \mathrm{C}$.

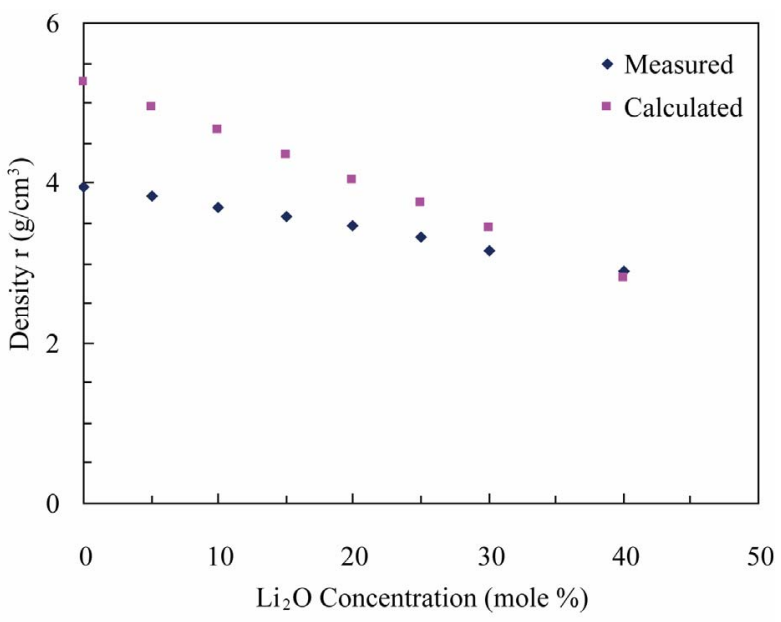

Figure 3. Variation of mass density relative to lithium oxide concentration (mole\%). 
Table 1. Variation of mass density, oxygen packing density, molar volume and lithium ion concentration with respect to glass composition in mole\%.

\begin{tabular}{|c|c|c|c|c|c|}
\hline \multirow{2}{*}{$\begin{array}{l}\text { Composition Mole \% } \\
\mathrm{Li}_{2} \mathrm{O}-\mathrm{CdO}-\mathrm{P}_{2} \mathrm{O}_{5}\end{array}$} & \multicolumn{2}{|c|}{ Density $\rho\left(\mathrm{g} / \mathrm{cm}^{3}\right)$} & \multirow{2}{*}{$\begin{array}{l}\text { Oxygen Paking Density } \\
\text { (g-atom/liter) }\end{array}$} & \multirow{2}{*}{$\begin{array}{l}\text { Molar Volume } V_{\mathrm{m}} \\
\quad\left(\mathrm{cm}^{3}\right)\end{array}$} & \multirow{2}{*}{$\begin{array}{l}\mathrm{Li}_{2} \mathrm{O} \text { ion Concentration } \\
\quad\left(\text { ion } / \mathrm{cm}^{3}\right) \times 10^{21}\end{array}$} \\
\hline & Calculated & Measured & & & \\
\hline $0 \%-50 \%-50 \%$ & 5.27 & 3.95 & 87.57 & 34.26 & 00.0 \\
\hline $05 \%-45 \%-50 \%$ & 4.96 & 3.83 & 86.05 & 34.87 & 1.73 \\
\hline $10 \%-40 \%-50 \%$ & 4.66 & 3.69 & 85.40 & 35.13 & 3.43 \\
\hline $15 \%-35 \%-50 \%$ & 4.35 & 3.57 & 84.33 & 35.58 & 5.08 \\
\hline $20 \%-30 \%-50 \%$ & 4.04 & 3.48 & 83.92 & 35.75 & 6.74 \\
\hline $25 \%-25 \%-50 \%$ & 3.74 & 3.34 & 82.50 & 36.36 & 8.28 \\
\hline $30 \%-20 \%-50 \%$ & 3.43 & 3.17 & 80.06 & 37.47 & 9.64 \\
\hline $40 \%-10 \%-50 \%$ & 2.82 & 2.89 & 76.42 & 39.26 & 12.27 \\
\hline
\end{tabular}

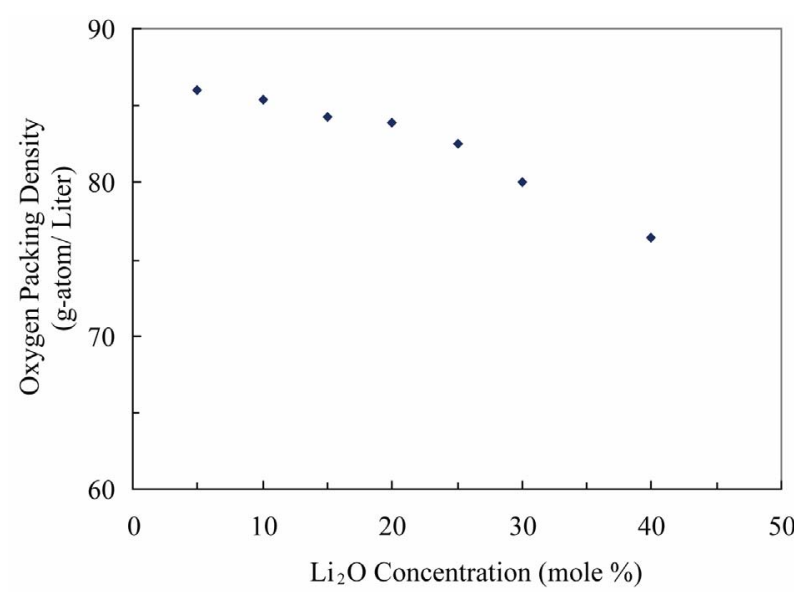

Figure 4. A plot of oxygen packing density as a function of lithium oxide content.

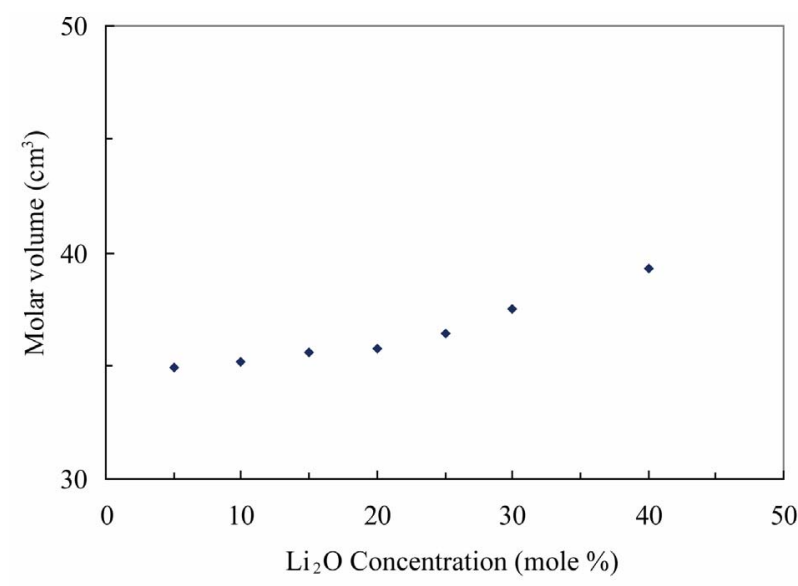

Figure 5. Variation of molar volume with lithium oxide concentration.

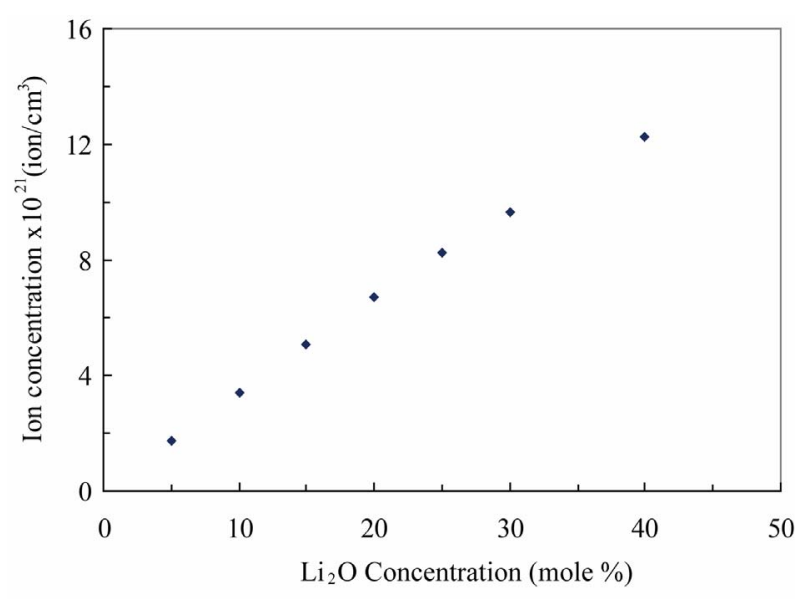

Figure 6. A graph between ion concentration of lithium and Lithium oxide content.

with increasing concentration of the lithium oxide. The replacement of an intermediate/modifier $\mathrm{CdO}$ with $\mathrm{Li}_{2} \mathrm{O}$ which is a modifier only, develops more non-bridging oxygen than bridging oxygen in the glass network $[15,16]$. The development of non-bridging oxygen may flayer-up the glass system and thus increases its molar volume. The increase in molar volume may cause decrease in oxygen packing density and mass density.

The results of modulus of rigidity ' $\eta$ ' of the lithium cadmium phosphate glasses are listed in Table $\mathbf{2}$ and are depicted graphically in Figure 7 as a function of Lithium Oxide concentration. The results show that ' $\eta$ ' decreases with increasing amount of $\mathrm{Li}_{2} \mathrm{O}$. The decrease in modulus of rigidity may be due to decrease in oxygen packing density $[10,12]$, which is a consequence of increasing number of non-bridging oxygen due to which 
Table 2. Variation of Modulus of rigidity, transition temperature softening temperature and coefficient of linear thermal expansion with respect to glass composition in mole\%.

\begin{tabular}{|c|c|c|c|c|c|}
\hline \multirow{2}{*}{$\begin{array}{l}\text { Composition Mole \% } \\
\mathrm{Li}_{2} \mathrm{O}-\mathrm{CdO}-\mathrm{P}_{2} \mathrm{O}_{5}\end{array}$} & \multicolumn{2}{|c|}{ Modulus Rigidity $\eta\left(\mathrm{dy} / \mathrm{cm}^{2}\right) \times 10^{11}$} & \multirow{2}{*}{$\begin{array}{l}\text { Transition Temperature } \\
\mathrm{T}_{\mathrm{g}}\left({ }^{\circ} \mathrm{C}\right)\end{array}$} & \multirow{2}{*}{$\begin{array}{l}\text { Softening Temperature } \mathrm{T}_{\mathrm{s}} \\
\left({ }^{\circ} \mathrm{C}\right)\end{array}$} & \multirow{2}{*}{$\begin{array}{l}\text { Coefficient Of linear } \\
\text { Expasion } \alpha\left({ }^{\circ} \mathrm{C}\right)^{-1}\end{array}$} \\
\hline & Unannealed samples & Annealed samples & & & \\
\hline $0 \%-50 \%-50 \%$ & 3.29 & 3.42 & 387 & 555 & 8.99 \\
\hline $05 \%-45 \%-50 \%$ & 3.17 & 3.19 & 350 & 490 & 9.52 \\
\hline $10 \%-40 \%-50 \%$ & 2.95 & 2.97 & 342 & 465 & 10.24 \\
\hline $15 \%-35 \%-50 \%$ & 2.78 & 2.82 & 330 & 445 & 11.11 \\
\hline $20 \%-30 \%-50 \%$ & 2.40 & 2.68 & 322 & 433 & 11.93 \\
\hline $25 \%-25 \%-50 \%$ & 2.63 & 2.57 & 315 & 425 & 12.70 \\
\hline $30 \%-20 \%-50 \%$ & 2.16 & 2.51 & ----- & ----- & ---- \\
\hline
\end{tabular}

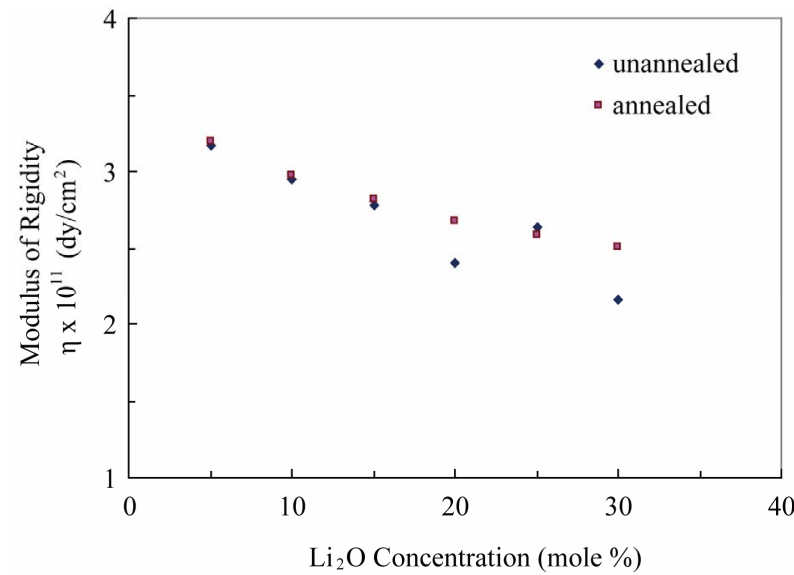

Figure 7. Dependence of modulus of rigidity on lithium oxide concentration.

the glass structure has further expanded.

The linear thermal expansion of these glasses is depicted in a representative Figure 2. The estimated values of transition temperature $T_{g}$, softening temperature $T_{s}$ and calculated values of coefficient of linear thermal expansion are listed in Table 2 and are depicted in Figures 8 and 9 respectively. $T_{g}$ and $T_{s}$ show a decreasing trend while coefficient of linear expansion increases with increasing concentration of $\mathrm{Li}_{2} \mathrm{O}$. In ternary lithium cadmium phosphate glasses a high coordination number modifier/intermediate is being replaced by a low coordination number modifier $\mathrm{Li}_{2} \mathrm{O}[2,14]$. The intermediate oxide $\mathrm{CdO}$ probably becomes the part of structure along with the glass former $\mathrm{P}_{2} \mathrm{O}_{5}$. The modifiers do not contribute to the network formation but essentially settle as interstices in the glass structure. The addition of alkali metal oxide cleaves the structure and disturbs the bonding between glass forming cations and oxygen anions.

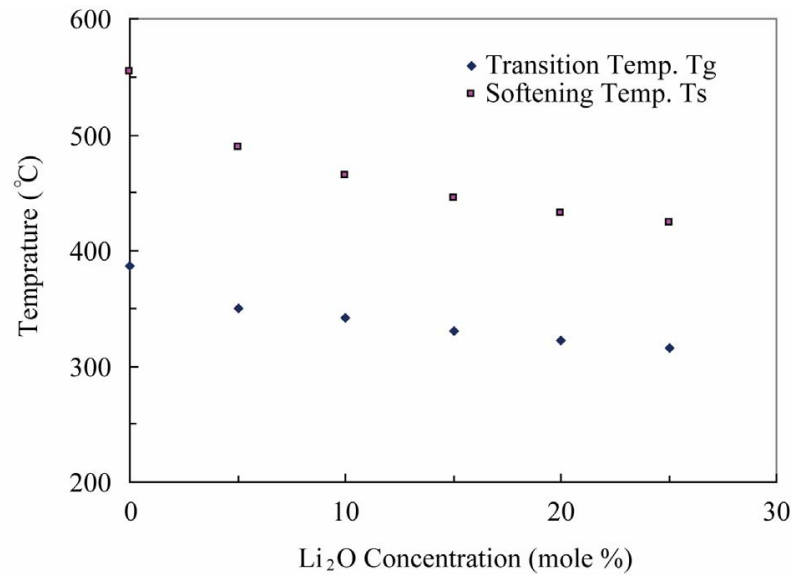

Figure 8. Graph illustrating the variation of Transition and Softening temperatures with the variation of lithium oxide concentration.

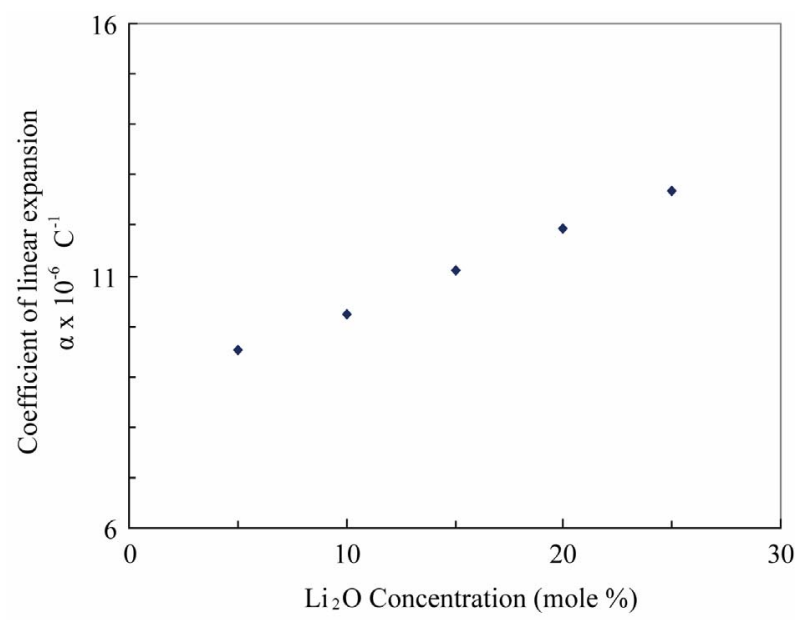

Figure 9. Variation of coefficient of linear expansion with respect to $\mathrm{Li} 2 \mathrm{O}$ concentration. 
This increase, the number of non-bridging oxygens and thus develop a more open structure. Consequently the structure expands the molar volume which causes a decrease in the oxygen packing density and hence a decrease in the density of the glass sample. The decrease in oxygen packing density along with the decrease of density and increase of molar volume of these glasses make them less mechanical resistive which may have caused an increase in the coefficient of linear expansion and decrease in the transition temperature and the softening temperature. The results reported here are similar to those reported by other research workers [13,15-17].

\section{References}

[1] M. Altaf, M. A. Chaudhry and S. A. Siddiqi, "Effect of $\mathrm{Li}_{2} \mathrm{O}$ on the Refractive Index and Optical Band Gap of Cadmium Phosphate Glasses," Journal of Materials Science and Technology, Vol. 12, No. 2, 2004, p. 150.

[2] S. A. Siddiqi, M. Masih and A. Mateen, "Optical Band Gap in Cd-Mg Phosphate Glasses," Materials Chemistry and Physics, Vol. 40, No. 1, 1995, pp. 69-72.

[3] B. Kumar, "Phosphate Glasses and Glass Ceramics Bio Materials," Indian Ceramic Society, Vol. 44, No. 6, 1985, p. 123.

[4] J. E. Pemberton, L. Latif Zadeh, J. P. Fletcher and S. H. Risbub, "Non-linear optical properties," Chemistry of Materials, Vol. 3, No. 1, 1991, p. 195.

[5] A. Mogus-Milankovic, A. Santic, A. Gajovic and D. E. Day, "Electrical Properties of Sodium Phosphate Glasses Containing $\mathrm{Al}_{2} \mathrm{O}_{3}$ and/or $\mathrm{Fe}_{2} \mathrm{O}_{3}$," Journal of Non-Crystalline Solids, Vol. 296, No. 1, 2001, pp. 57-64.

[6] M. Ahmad, F. Salman, M. Morsi, K. El-Badry and F. Metwall, "Electrical Proties of Some Copper-Containing
Phosphate Glasses," Journal of Materials Science, Vol. 41, No. 5, 2006, pp. 1667-1669.

[7] A. Pan and A. Ghosh, "Structural and Optical Properties of Lithium Bismuthate Glasses," Materials Research Society, Vol. 17, No. 8, 2002, p. 1941.

[8] G. Y. Guo and Y. L. Chen, "Optical Properties of a Chemically Durable Phosphate Glass," Journal of Materials Science Letters, Vol. 12, No. 5, 1993, pp. 265-267.

[9] G. W. Morey, "The Properties of Glasses," 2nd Edition, Reinhold Publishing Corporation, New York, 1960.

[10] D. G. Holloway, “The Physical Properties of Glass," Wykeham Publications Ltd., London, 1973.

[11] W. D. Kingery, "Introduction to Ceramics," John Willy and Sons, Inc., NewYork, 1960.

[12] M. A. Chaudhry and M. Altaf, "Electrical Properties of $\mathrm{Na}_{2} \mathrm{O}-\mathrm{CdO}-\mathrm{P}_{2} \mathrm{O}_{5}$ Glasses," Modern Physics Letters B, Vol. 14, No. 9, 2000, pp. 319-326.

[13] M. Altaf and M. A. Chaudhry, "Study of Some Physical Properties of Cadmium Lanthanum Phosphate Glasses," Journal of Materials Science and Technology, Vol. 13, No. 1, 2005, p. 33.

[14] K. Othmer, "Encyclopedia of Chemical Technology," Clanrendon Press, Oxford, Vol. 11, 1963.

[15] D. S. Rao and P. P. Karat, "Elastic Constants of Glasses in the System $\mathrm{P}_{2} \mathrm{O}_{5}-\mathrm{Na}_{2} \mathrm{O}-\mathrm{ZnO}$," Physics \& Chemistry of Glasses, Vol. 35, No. 3, 1994, p. 124.

[16] A. P. N. de Oliveira, L. B., C. Leonelli, T. Manfredini, and G. C. Pellacani, "Physical Properties of Quenched Glasses in the $\mathrm{Li}_{2} \mathrm{O}-\mathrm{ZrO}-\mathrm{SiO}_{2}$ System," Journal of American Ceramic Society, Vol. 79, No. 4, 1996, pp. 10921097.

[17] M. Farley and G. A. Saunders, "The Application of Small Polaron Theory to Transition Metaloxide Theory," Physica Status Solidi (a), Vol. 28, 1975, p. 199. 